\title{
Vínculos organizacionais de comprometimento, entrincheiramento e consentimento: explorando seus antecedentes e consequentes
}

\author{
Gean Carlos Tomazzoni ${ }^{1}$ \\ VÂNia MEdianeira Flores COSTA ${ }^{2}$ \\ 1 Universidade Federal do Rio Grande do Sul (UfrgS) / Programa de Pós-Graduação em Administração, Porto Alegre - RS, Brasil \\ ${ }^{2}$ Universidade Federal de SANTA Maria (UFSM) / Departamento de CIÊnCIAS AdMINISTRATIVAS, SANTA MARIA - RS, BRASIL
}

\begin{abstract}
Resumo
Este trabalho tem por objetivo desenvolver um modelo que analise as influências dos valores organizacionais nos vínculos de comprometimento, entrincheiramento e consentimento do indivíduo com a organização, como variáveis antecedentes, e o desempenho no trabalho, como variável consequente. Para alcançar o objetivo traçado, realizou-se uma pesquisa de natureza descritiva e explicativa, com abordagem de métodos mistos - quantitativos e qualitativos. A pesquisa foi estruturada em duas fases. Na primeira fase, os dados foram coletados a partir da aplicação de um questionário de pesquisa fechado. Para os dados quantitativos, a análise foi operacionalizada por meio da técnica de modelagem de equações estruturais. Na segunda fase, os dados foram coletados por meio de entrevistas semiestruturadas. A análise dos dados qualitativos foi realizada por meio da técnica de análise de conteúdo. Os resultados revelam que determinados valores compartilhados pela organização são determinantes do tipo de vínculos que o indivíduo estabelece com a organização, sendo que valores distintos influenciam vínculos distintos. Ademais, como consequente, o tipo de vínculo organizacional estabelecido influencia o desempenho do indivíduo no trabalho.
\end{abstract}

Palavras-chave: Comprometimento organizacional. Entrincheiramento organizacional. Consentimento organizacional. Valores organizacionais. Desempenho no trabalho.

\section{Antecedents and consequences of organizational commitment, entrenchment, and consent}

\begin{abstract}
This study aims to develop a model that analyzes the influence of organizational values as antecedent variables of the individuals' commitment, entrenchment and consent with the organization, and work performance as the consequent variable of this relationship between individuals and organizations. Descriptive and conclusive research was carried out using a quantitative and qualitative approach. The research was structured in two phases. In the first phase, the data were collected from the application of a closed questionnaire. For the quantitative data, the analysis was operationalized by means of the modeling technique of structural equations. In the second phase, data were collected through semistructured interviews. The analysis of the qualitative data was carried out using the technique of content analysis. The results reveal that certain values shared by the organization are determinants of the type of linkages that the individual develops with the organization, with different values influencing different linkages. Also, as a consequence, the type of organizational link established influences the performance of the individual at work.
\end{abstract}

Keywords: Organizational commitment. Organizational entrenchment. Organizational consent. Organizational values. Work performance.

\section{Vínculos organizacionales de compromiso, atrincheramiento y consentimiento: explorando sus antecedentes y consecuentes}

\section{Resumen}

Este trabajo tiene por objetivo desarrollar un modelo que analice las influencias de los valores organizacionales en los vínculos de compromiso, atrincheramiento y consentimiento del individuo con la organización como variables antecedentes y el desempeño en el trabajo como variable consecuente. Para alcanzar el objetivo trazado se realizó una investigación de naturaleza descriptiva y explicativa, con el empleo de métodos mixtos - cuantitativos y cualitativos. La investigación fue estructurada en dos fases. En la primera fase, los datos fueron recolectados a partir de un cuestionario de encuesta cerrado. Para los datos cuantitativos, el análisis fue realizado por medio de la técnica de modelado de ecuaciones estructurales. En la segunda fase, los datos fueron recolectados por medio de la realización de entrevistas semiestructuradas. El análisis de los datos cualitativos se realizó con el empleo de la técnica de análisis de contenido. Los resultados revelan que ciertos valores compartidos por la organización son determinantes del tipo de vínculos que el individuo desarrolla con la organización y valores distintos influencian vínculos distintos. Aún, como consecuente, el tipo de vínculo organizacional establecido influye en el desempeño del individuo en el trabajo.

Palabras clave: Compromiso organizacional. Atrincheramiento organizacional. Consentimiento organizacional. Valores organizacionales. Rendimiento en el trabajo. 


\section{INTRODUÇÃO}

O avanço das lentes teóricas sobre as relações estabelecidas entre o indivíduo e a organização possibilitou a descoberta de outros tipos de vínculos de natureza distinta daquela do comprometimento, como o entrincheiramento e o consentimento organizacionais, delimitando o comprometimento com sua vertente de natureza afetiva (BASTOS e AGUIAR, 2015; PINHO, BASTOS e ROWE, 2015a). Considerando o comprometimento um tipo particular de vínculo psicológico, Klein, Molloy e Brinsfield (2012) reconhecem que outros vínculos também são importantes e, em determinados contextos, podem ser mais apropriados. Desse modo, os autores defendem a necessidade de trabalhos que almejam compreender outros tipos de vínculos psicológicos e, idealmente, entender e prever quais tipos são mais desejáveis em determinado contexto. Ao compreender que são vínculos distintos entre si, ressalta-se a necessidade da ampliação dos conhecimentos sobre seus antecedentes e consequentes. Parte-se, portanto, da importância de compreender como esses vínculos distintos se diferenciam entre si e desenvolvem diferentes resultados para a organização.

Os valores organizacionais podem predizer diferentes vinculações do indivíduo com a organização, caracterizando-se como fatores antecedentes desses vínculos. Tamayo (2005) compreende que os valores se operacionalizam como princípios e metas priorizados que exercem influência sobre o comportamento, como uma base capaz de orientar e guiar a vida dos indivíduos, seja de modo direto, seja de modo indireto, espelhando-se em suas ações. Desse modo, diferentes princípios e metas priorizados pela organização podem predizer diferentes tipos - comprometimento, entrincheiramento e consentimento - e níveis de vínculos estabelecidos pelo indivíduo com a organização. Portanto, analisar as questões relativas aos vínculos entre indivíduo e organização significa levar em consideração os fatores que consigam explicar seus desencadeadores, como os valores organizacionais, buscando compreender o desenvolvimento dos laços afetivos (comprometimento), instrumentais (entrincheiramento) e normativos (consentimento).

O trabalhador que internaliza os valores da organização se identifica com seus objetivos, envolve-se com os papéis de trabalho e deseja permanecer trabalhando para ela, características de que foi desenvolvida uma ligação psicológica, um vínculo do trabalhador com sua organização (MOWDAY, PORTER e STEERS, 1982; PINHO, 2009). Considerando que o comprometimento, entrincheiramento e consentimento são vínculos distintos, compreende-se que possam ser explicados por valores organizacionais também distintos. A característica dinâmica atribuída à noção de comprometimento pressupõe o compartilhamento de valores que enfatizam pensamentos e ações independentes que favorecem o processo de mudança, desafios e variedade no trabalho, criatividade, inovação e o trabalho de maneira colaborativa. 0 entrincheiramento, por sua vez, como vínculo instrumental de permanência do indivíduo por necessidade, pode ser estimulado por valores relativos à proteção da estabilidade, bem como por valores que priorizem os interesses individuais do trabalhador. $O$ consentimento, como vínculo passivo, que pressupõe o cumprimento de ordens de maneira automática, pode ser estimulado por valores que priorizem estruturas autocráticas, rígidas e inflexíveis, onde prevalecem atitudes de cumprimento de ordens e normas, sem abertura para a inovação e autonomia do trabalhador.

Acerca dos consequentes dos vínculos do indivíduo com a organização, Medeiros e Albuquerque (2005, p. 27) esclarecem que os estudos sobre o comprometimento se baseiam em uma premissa básica comum que norteia as pesquisas: "um elevado nível de comprometimento contribui para que as empresas atinjam seus objetivos organizacionais e consequentemente melhor desempenho." Scheible e Bastos (2013) complementam que, apesar dos estudos que evidenciam a importância do comprometimento nos resultados organizacionais, muitas questões ainda representam desafios para pesquisadores e gestores. A necessidade de aprofundar a influência dos vínculos organizacionais sobre o desempenho no trabalho é reforçada com o surgimento das novas abordagens que delimitam o comprometimento à sua base afetiva e desenvolvem novos construtos entrincheiramento e consentimento.

Nesse contexto, o objetivo deste artigo consiste em desenvolver um modelo que analise as influências dos valores organizacionais nos vínculos de comprometimento, entrincheiramento e consentimento do indivíduo com a organização, como variáveis antecedentes, e o desempenho no trabalho, como variável consequente. 


\section{REFERENCIAL TEÓRICO}

\section{Vínculos organizacionais de comprometimento, entrincheiramento e consentimento}

O comprometimento representa uma construção central no campo de estudo do comportamento organizacional e tem sido argumentado como mais relevante hoje do que nunca (KLEIN, MOLLOY e BRINSFIELD, 2012). Apesar da natureza dinâmica das relações de trabalho, as organizações precisam de uma força de trabalho comprometida e a maioria das pessoas quer se comprometer com algo (KLEIN, 2016). O comprometimento, em toda a sua gama de metas do local de trabalho - carreira, equipe, organização etc. - continua sendo um determinante importante dos resultados das organizações. No nível organizacional, ter uma força de trabalho comprometida se associa a maiores níveis de desempenho organizacional, margens de lucro e satisfação dos clientes (CAMERON, BRIGHT e CAZA, 2004; HARTER, SCHMIDT, ASPLUND et al., 2010; HEAVEY, HOLWERDA e HAUSKNECHT, 2013). Acerca dos benefícios individuais do comprometimento, Gao-Urhahn, Biemann e Jaros (2016) constataram que os trabalhadores com maior comprometimento provavelmente obterão um nível mais alto de renda.

O comprometimento organizacional é frequentemente definido como uma ligação, vínculo ou apego do indivíduo à organização (MAIA, BASTOS e SOLINGER, 2016). No modelo tridimensional proposto por Meyer e Allen (1991), o comprometimento é compreendido a partir de três concepções que explicam a ligação do indivíduo com a organização. A primeira base, denominada afetiva, representa o desejo do indivíduo querer permanecer na organização por um sentimento de apego efetivo, que destaca a natureza emocional do vínculo entre a pessoa e a organização (MEYER e ALLEN, 1991). A segunda base representa a obrigação, em que os funcionários se sentem moralmente obrigados a permanecer, referindo-se a uma vinculação organizacional normativa (MEYER e ALLEN, 1991). A terceira base é de conscientização de custos, em que os indivíduos percebem seus investimentos específicos na organização e não têm alternativas para mudar para outro lugar, referindo-se ao vínculo organizacional contínuo ou instrumental (MEYER e ALLEN, 1991).

Embora haja predominância desse modelo nas pesquisas nacionais e internacionais, a estrutura tridimensional está longe de representar um consenso entre pesquisadores, principalmente no que se refere às bases instrumental e normativa (BALSAN, COSTA, BASTOS et al., 2017). A inconsistência da estrutura tridimensional e a ampliação teórica e empírica sobre o tema consolidam a sustentação de que o vínculo de natureza afetiva se diferencia fortemente do vínculo instrumental e normativo (BASTOS e AGUIAR, 2015; PINHO, BASTO e ROWE, 2015b). Desse modo, surgem as discussões acerca da dimensionalidade do comprometimento ao integrar à sua definição as noções de permanência do indivíduo por necessidade, por obrigação ou devido à perda de investimentos ou custos pessoais em caso de saída e limitação de opções de trabalho. Emerge, assim, a necessidade de tratá-los como fenômenos que não podem ser denominados comprometimento, dando origem a dois novos construtos, o entrincheiramento organizacional (RODRIGUES e BASTOS, 2015) e o consentimento organizacional (SILVA e BASTOS, 2015).

Para explorar a complexidade do fenômeno, assume-se neste artigo o comprometimento como vínculo de natureza afetiva (MOWDAY, PORTER e STEERS, 1982), considerando que essa base é conceitualmente menos controversa, associada mais fortemente com os comportamentos desejáveis no trabalho (PINHO, BASTOS e ROWE 2015a) e consistente com a proposta de mensuração do construto desenvolvida por Bastos e Aguiar (2015). Ademais, argumenta-se que os vínculos instrumental e normativo devem ser explorados como fenômenos distintos do comprometimento, denominados entrincheiramento e consentimento, respectivamente.

O conceito de entrincheiramento foi tratado inicialmente no campo de estudos das carreiras por Carson e Bedeian (1994), introduzido pelos autores para diferenciar o comprometimento da tendência do indivíduo continuar em uma mesma ocupação, devido aos investimentos realizados na carreira, custos emocionais a serem perdidos em caso de mudança de ocupação e percepção limitada de caminhos alternativos fora do campo de atuação profissional. Partindo das pesquisas sobre entrincheiramento na carreira, a adaptação do conceito ao contexto das organizações, realizado por Rodrigues e Bastos (2012), partiu da mesma base teórica que é utilizada para tratar o comprometimento de instrumental, fundamentada no sentido de trocas materiais (BECKER, 1960), embutido no construto do entrincheiramento.

O entrincheiramento organizacional é definido por Rodrigues e Bastos (2015) como uma tendência do indivíduo permanecer na organização, devido a possíveis perdas de investimentos e custos associados à sua saída e à percepção de limitações de alternativas no mercado de trabalho. Além disso, a essência do entrincheiramento do indivíduo com a organização se encontra na noção de estar preso por não conseguir visualizar uma alternativa que o sustente de acordo com suas 
necessidades e expectativas. Essa definição, sustentada neste artigo, operacionaliza-se na medida do construto, que integra três dimensões analíticas: ajustamento à posição social, arranjos burocráticos impessoais e limitações de alternativas (RODRIGUES e BASTOS, 2015).

Os ajustamentos à posição social se referem aos investimentos do indivíduo nas condições necessárias à sua adaptação, a exemplo de treinamentos para desempenho de atividades específicas, que contribuiriam para o seu ajuste e reconhecimento na organização e que seriam perdidos caso a deixasse. Os arranjos burocráticos impessoais compreendem a estabilidade financeira e benefícios que seriam perdidos se o indivíduo saísse da organização, como férias e feriados pagos, entre outros. A limitação de alternativas refere-se à percepção de restrições no mercado de trabalho e de falta de alternativas caso o indivíduo saísse da organização (RODRIGUES e BASTOS, 2015).

O construto do consentimento encontra na literatura da psicologia social e sociologia seus pilares teóricos, caracterizado pelo vínculo entre indivíduo e organização estabelecido a partir de uma perspectiva que, descartando elementos afetivos e psicológicos, enfatiza as relações de controle e autoridade que induzem o trabalhador a obedecer ou cumprir o papel de subordinado dele esperado (PINHO, BASTOS e ROWE, 2015a). O vínculo de consentimento organizacional pressupõe que o trabalhador consente com as demandas organizacionais, acata integramente as ordens estabelecidas e não se considera responsável por nenhuma consequência, principalmente negativa, que possa advir de suas ações (SILVA e BASTOS, 2015).

Esse novo construto tem sido estudado muito recentemente por Silva e Bastos (2015) por meio de uma nova proposta de escala de mensuração. $O$ conceito de consentimento organizacional, que norteia esta pesquisa, baseia-se na definição proposta por Silva e Bastos (2015), que delimitam o consentimento à noção de tendência do indivíduo de comportar-se de acordo com as ordens estabelecidas por seu superior que representa a organização, entendendo que esse é seu papel no trabalho.

\section{Valores organizacionais}

No âmbito organizacional, os valores envolvem princípios ou crenças hierarquicamente sistematizados e relacionados às metas e aos comportamentos organizacionais que se identificam como desejáveis (PAIVA e DUTRA, 2017). Assim, os valores são definidos por Tamayo e Gondim (1996, p. 63) como "princípios ou crenças, organizados hierarquicamente, relativos a tipos de estrutura ou a modelos de comportamentos desejáveis que orientam a vida da empresa e estão a serviço de interesses individuais, coletivos ou mistos."

Partindo de uma abordagem de análise dos valores organizacionais baseada na percepção dos membros da organização, que identifica os valores existentes e praticados, Oliveira e Tamayo (2004) testaram empiricamente a hipótese de que as motivações que sustentam os sistemas de valores pessoais também se aplicam à esfera organizacional. Para tal, os autores se pautaram na estrutura dos valores pessoais desenvolvida por Schwartz (1992).

Na teoria de Schwartz (1992) os tipos motivacionais de valores estão organizados em duas dimensões. A dimensão abertura à mudança versus conservação apresenta no primeiro polo valores relativos a pensamentos e ação independentes - Estimulação, Autodeterminação e Hedonismo - e no polo conservação, valores que dão ênfase à autorrestrição, preservação de práticas tradicionais e proteção da estabilidade - Segurança, Conformidade e Tradição. A segunda dimensão, autopromoção versus autotranscedência, opõe valores relativos, que privilegiam os interesses do indivíduo, mesmo às custas dos outros - Poder, Realização e Hedonismo - em oposição à preocupação com o bem-estar dos outros e da natureza - Universalismo e Benevolência.

Ao buscar transpor a perspectiva teórica de valores individuais para os valores organizacionais, Oliveira e Tamayo (2004) propõem o Inventário de Valores Organizacionais. Perante tal proposta, Tamayo (2005) complementa que os valores pessoais expressam metas da pessoa, os valores organizacionais se referem às metas da organização, sendo que ambos se caracterizam como princípios que orientam e guiam a vida de pessoas e grupos, constituídos de componentes motivacional, cognitivo, hierárquico e social.

O Quadro 1 apresenta a correspondência entre os valores individuais de Schwartz (1992) e os valores organizacionais de Oliveira e Tamayo (2004). 
Quadro 1

Correspondência entre os valores individuais e organizacionais

\begin{tabular}{|c|c|l|}
\hline Valores organizacional & Correspondência & \multicolumn{1}{c|}{ Metas organizacionais } \\
\hline Autonomia & $\begin{array}{c}\text { Autodeterminação } \\
\text { Estimulação }\end{array}$ & $\begin{array}{l}\text { Oferecer desafios e variedade no trabalho, estimular a curiosidade, criatividade } \\
\text { e a inovação. }\end{array}$ \\
\hline Bem-estar & Hedonismo & Promover a satisfação, o bem-estar e a qualidade de vida no trabalho. \\
\hline Realização & Realização & Valorizar a competência e o sucesso dos trabalhadores. \\
\hline Domínio & Poder Social & Obter lucros, ser competitiva e dominar o mercado. \\
\hline Prestígio & Poder Social & $\begin{array}{l}\text { Ter prestígio, ser conhecida e admirada por todos, oferecer produtos e serviços } \\
\text { satisfatórios para os clientes. }\end{array}$ \\
\hline Tradição & Tradição & \begin{tabular}{l} 
Manter a tradição e respeitar os costumes da organização. \\
\hline Conformidade
\end{tabular} \\
\hline $\begin{array}{c}\text { Conformidade } \\
\text { a Coletividade }\end{array}$ & $\begin{array}{l}\text { Promover a correção, a cortesia e as boas maneiras no trabalho e o respeito } \\
\text { às normas da organização. }\end{array}$ \\
\hline Benevolência & $\begin{array}{l}\text { Promover a justiça e a igualdade na organização, bem como a tolerância, a } \\
\text { sinceridade e a honestidade. }\end{array}$ \\
\hline
\end{tabular}

Fonte: Adaptado de Oliveira e Tamayo (2004).

De acordo com Tamayo e Gondim (1996), para compreender os valores organizacionais é necessário se ater às lentes dos trabalhadores, porque eles estão ligados à organização e, portanto, suas percepções representam a realidade organizacional. Dessa forma, as percepções individuais constituem o núcleo central dos valores compartilhados pelos membros da organização, capaz de atingir a periferia hierárquica de prioridade axiológica (NASCIMENTO, ADAID-CASTRO, CARVALHO et al., 2016). É com base nessa prerrogativa, que sustenta o modelo de Oliveira e Tamayo (2004), que este estudo fundamenta suas lentes teóricas para análise dos valores organizacionais.

\section{Desempenho no trabalho}

$\mathrm{Na}$ literatura sobre a temática existe consenso entre pesquisadores de que o conceito de desempenho integra aspectos comportamentais e aspectos de resultado (CAMPBELL, 1990; SONNENTAG e FRESE, 2002). A dimensão comportamental se refere ao que o indivíduo faz na situação de trabalho, enquanto a dimensão de resultado se refere à consequência do comportamento individual (FOGAÇA, REGO, MELO et al., 2018). O desempenho das tarefas é uma das dimensões gerais do desempenho no trabalho e é tradicionalmente considerada em estudos seminais sobre avaliação de trabalhadores. No entanto, apenas recentemente o papel dos aspectos relacionais ganhou espaço nas agendas de pesquisa sobre desempenho (MACIEL e CAMARGO, 2016).

Um dos modelos clássicos de referência na área foi desenvolvido por Campbell (1990), que estruturou os componentes do desempenho em função de três grandes determinantes: o conhecimento declarativo, relacionado a fatos, princípios, metas, interesses, capacidades e experiência; o conhecimento procedimental, que se vincula às habilidades cognitivas, psicomotoras e sociais necessárias ao desempenho da tarefa; e a motivação, que compreende o nível de esforço despendido pelo indivíduo e seu grau de persistência no desempenho.

Para Campbell (1990), desempenho se refere à ação em si e não apenas a sua consequência ou seu resultado. Partindo da taxonomia proposta pelos trabalhos liderados por Campbell (1990), os pesquisadores Sonnentag e Frese (2002) operacionalizam o construto, associando-o a fatores de nível individual - querer fazer - relacionados à tarefa - saber fazer - ao contexto poder fazer - dividindo o desempenho em duas facetas: desempenho para tarefas e para o contexto.

A dimensão desempenho voltado para tarefa é multidimensional, englobando cinco fatores: 1) proficiência em tarefa específica de um trabalho; 2) proficiência em tarefas não específicas de um trabalho; 3) proficiência em comunicação escrita e oral; 4) supervisão; e 5) gestão/administração. Segundo Queiroga, Borges-Andrade e Coelho Junior (2015), o desempenho voltado para tarefa representa a forma como o indivíduo contribui para os aspectos técnicos da organização, a partir da realização das suas atividades laborais, podendo a contribuição ocorrer de forma direta (voltada para a produção) ou de forma indireta (voltada para a gestão). 
O desempenho contextual, com base em Sonnentag e Frase (2002), pode desdobrar-se em dois tipos de desempenho: comportamentos que buscam, em essência, o bom funcionamento da organização e comportamentos proativos direcionados à mudança e ao aperfeiçoamento dos processos laborais e organizacionais. Para a realização deste estudo, parte-se do modelo proposto por Queiroga, Borges-Andrade e Coelho Junior (2015), buscando analisar o desempenho no trabalho a partir das dimensões desempenho voltado para o contexto e desempenho voltado para a tarefa.

\section{MÉTODO DO ESTUDO}

Este estudo se caracteriza como uma pesquisa de natureza descritiva e explicativa, com o emprego de abordagem de métodos mistos. Dadas as suas características, a pesquisa foi dividida em duas fases: fase I - quantitativa; e fase II - qualitativa.

Participaram desta pesquisa organizações, de natureza privada, pertencentes ao setor varejista, localizadas nos shopping centers de Santa Maria-RS. A escolha do campo de pesquisa se deu pela multiplicidade de realidades organizacionais, que caracteriza os diferentes empreendimentos que integram o espaço de um shopping center. Assim, foi possível tecer uma análise explicativa de como os construtos aqui investigados se apresentam e se relacionam, considerando o contexto distinto de cada organização pesquisada. Desse modo, a pesquisa contou com a participação das organizações dos quatro shopping centers da cidade, que atenderam aos critérios estabelecidos. As características comuns das organizações participantes são: I - pertencer ao setor varejista; II - manter suas atividades nos shopping centers participantes; III - possuir uma equipe de trabalho com no mínimo 4 funcionários; e IV - consentir em participar deste estudo.

$\mathrm{Na}$ fase I, a população se constituiu pela soma absoluta de todos os funcionários das organizações participantes. Alinhado com a técnica de análise de dados de modelagem de equações estruturais, a partir do SmartPLS, para estimação da amostra, considerando a análise do poder estatístico, utilizou-se o programa computacional $G{ }^{*}$ Power 3 . Definiu-se nível de significância de $5 \%$ e poder estatístico de $80 \%$, e tamanho do efeito (f2) definido em $15 \%$, seguindo os parâmetros sugeridos por Hair Junior, Hult, Ringle et al. (2013). Seguindo tais parâmetros, a amostra deveria ser composta por no mínimo 85 indivíduos respondentes do questionário de pesquisa, entretanto, foram coletados 260 questionários válidos. A aplicação dos questionários ocorreu de forma presencial, no período de setembro a novembro de 2016.

Para a coleta de dados, na fase I, utilizou-se um instrumento de pesquisa com itens fechados, composto por quatro partes: Parte I - dados pessoais e ocupacionais; Parte II - vínculos organizacionais de comprometimento (BASTOS e AGUIAR, 2015), entrincheiramento (RODRIGUES e BASTOS, 2015) e consentimento (SILVA e BASTOS, 2015); Parte III - valores organizacionais (OLIVEIRA e TAMAYO, 2004); Parte IV - desempenho no trabalho (QUEIROGA, BORGES-ANDRADE e COELHO JUNIOR, 2015).

Para testar as relações de influência entre os construtos, utilizou-se a técnica de modelagem de equações estruturais baseada em modelos de estimação de ajuste de mínimos quadrados parciais, a partir do SmartPLS, seguindo a sequência didática proposta por Rigle, Silva e Bido (2014). Salienta-se que, inicialmente, realizou-se a análise fatorial confirmatória das escalas de mensuração. Nessa etapa, foram excluídas variáveis que apresentaram cargas fatoriais baixas e não se adequaram ao modelo proposto.

Com base na literatura, almejando por meio deste estudo explicar em maior detalhe os fundamentos teóricos que justificam as relações entre os construtos, foram elaboradas as seguintes hipóteses de pesquisa:

- $\quad \mathbf{H 1}$ - Trabalhadores que compartilham valores onde os tipos motivacionais dos polos autotranscedência (preocupação com a coletividade) e abertura (autonomia e bem-estar) são mais fortes, estabelecem predominantemente o vínculo de comprometimento organizacional.

- H2 - Trabalhadores que compartilham valores onde os tipos motivacionais dos polos autopromoção (bem-estar, realização e domínio) e conservação (tradição e conformidade) são mais fortes, estabelecem predominantemente o vínculo de entrincheiramento organizacional.

- H3-Trabalhadores que compartilham valores onde os tipos motivacionais do polo conservação (tradição e conformidade) são mais fortes, estabelecem predominantemente o vínculo de consentimento organizacional.

- H4 - Trabalhadores que estabelecem padrões de vínculos onde o comprometimento organizacional é mais forte apresentam melhor desempenho no trabalho.

- H5 - Trabalhadores que estabelecem padrões de vínculos onde o entrincheiramento e consentimento organizacionais são mais fortes apresentam menor desempenho no trabalho. 
Na fase II da pesquisa participaram gestores das organizações, com os quais foram realizadas entrevistas. A seleção dos participantes se deu a partir dos resultados preliminares da fase I. Assim, foram selecionados para participar dessa fase os gestores das organizações que apresentaram maiores níveis de vínculos organizacionais, mensurados por meio do cálculo da média geral da equipe de funcionários para os três construtos - comprometimento, entrincheiramento e consentimento. A quantidade de entrevistas foi delimitada pelo critério da saturação teórica, assim, contabilizou-se a participação de 10 gestores entrevistados. As entrevistas foram realizadas presencialmente em janeiro de 2017 . O roteiro de entrevista foi elaborado a partir de um conjunto de fichas, que representam características conceituais dos vínculos organizacionais, desenvolvidas pelo estudo de Pinho (2009). A partir dessas fichas, foram exploradas as associações com os valores organizacionais (OLIVIERA e TAMAYO, 2004) e o desempenho no trabalho (QUEIROGA, BORGES-ANDRADE e COELHO JUNIOR, 2015).

Os dados provenientes das entrevistas foram submetidos à técnica de análise de conteúdo, com base em Bardin (2011). As principais categorias de análise foram definidas a priori, espelhando os modelos teóricos adotados, porém, mantendo abertura para outras possibilidades contidas nos relatos dos entrevistados. As categorias foram operacionalizadas considerando as noções acerca dos antecedentes e consequentes dos vínculos do indivíduo com a organização, centrando-se em suas associações com os valores organizacionais e o desempenho no trabalho.

\section{RESULTADOS E DISCUSSÕES}

Os resultados foram estruturados em duas seções, organizadas de acordo com as fases da pesquisa.

\section{Fase I - Modelagem de equações estruturais}

Para testar as relações de influência entre os construtos, inicialmente, realizou-se a análise do modelo de mensuração. A Tabela 1 apresenta os valores encontrados para os indicadores alfa de Cronbach e variância média extraída, que garantem a validade convergente e a confiabilidade do modelo de mensuração.

Tabela 1

Validades convergentes e confiabilidade do modelo ajustado

\begin{tabular}{l|c|c}
\hline \multicolumn{1}{c|}{ Construtos } & Alfa de Cronbach & $\begin{array}{c}\text { Variância média } \\
\text { extraída }\end{array}$ \\
\hline Comprometimento & 0,911 & 0,507 \\
\hline Entrincheiramento - Ajustamento à Posição Social & 0,764 & 0,515 \\
\hline Entrincheiramento - Arranjos Burocráticos Impessoais & 0,702 & 0,526 \\
\hline Entrincheiramento - Limitação de Alternativas & 0,878 & 0,622 \\
\hline Consentimento & 0,857 & 0,584 \\
\hline Valor - Autonomia & 0,752 & 0,503 \\
\hline Valor - Bem-Estar & 0,799 & 0,501 \\
\hline Valor - Conformidade & 0,695 & 0,522 \\
\hline Valor - Domínio & 0,720 & 0,542 \\
\hline Valor - Preocupação com a Coletividade & 0,874 & 0,570 \\
\hline Valor - Prestígio & 0,762 & 0,584 \\
\hline Valor - Realização & 0,788 & 0,611 \\
\hline Valor - Tradição & 0,762 & 0,677 \\
\hline Desempenho - Voltado ao Contexto & 0,892 & 0,571 \\
\hline Desempenho - Voltado à Tarefa & 0,864 & 0,596 \\
\hline
\end{tabular}

Fonte: Elaborada pelos autores.

Os indicadores de confiabilidade apresentam valores satisfatórios, ou seja, índices acima de 0,7 (HAIR JUNIOR, HULT, RINGLE et al., 2013). Acerca das validades convergentes, verifica-se que os valores das variâncias médias extraídas (AVE) são superiores a 0,5, assim, admite-se que o modelo convirja a um resultado satisfatório.

Para a análise da validade discriminante foram utilizados dois indicadores. O primeiro, de Fornell e Larcker (1981), que estabelece que as raízes quadradas das AVE devem ser maiores do que as correlações entre as variáveis latentes. E o segundo, 
que verifica as cargas cruzadas, para as quais se orienta pelo critério de Chin (1998), que determina que a carga fatorial mais alta de cada variável observada deve estar associada à sua respectiva variável latente. Nos dois critérios se observou a validade discriminante do modelo de mensuração.

Finalizado o processo de ajuste do modelo de mensuração, realizou-se a análise do modelo estrutural. A análise dos fatores de inflação da variância (VIF) demonstrou que nenhuma das variáveis latentes apresenta problemas de multicolinearidade, ou seja, foram identificados valores de VIF < 5 para todos os construtos (HAIR JUNIOR, HULT, RINGLE et al., 2013).

Ainda nessa etapa foram avaliados os indicadores de qualidade de ajuste do modelo: relevância ou validade preditiva $\left(Q^{2}\right)$ ou indicador de Stone-Geisser e tamanho do efeito $\left(\mathrm{f}^{2}\right)$ ou indicador de Cohen (1998). Seguindo os critérios estabelecidos por Hair Junior, Hult, Ringle et al. (2013), os dados demostraram que todos os indicadores atendem ao critério de validade preditiva, sendo todos os índices superiores a zero. Já para o tamanho do efeito $\left(\mathrm{f}^{2}\right)$, índices de $0,02,0,15$ e 0,35 são considerados pequenos, médios e grandes, respectivamente (HAIR JUNIOR, HULT, RINGLE et al., 2013). Seguindo tais parâmetros, o tamanho do efeito das variáveis latentes deste estudo pode ser classificado como alto ou moderado. No geral, os valores de $Q^{2}$ e $f^{2}$ confirmam que o modelo tem acurácia e que os construtos são importantes para o ajuste geral. Para finalizar a análise do modelo estrutural, avaliou-se o ajuste geral, por meio do índice de adequação (goodness of fit) proposto por Tenenhaus, Vinzi, Chatelin et al. (2005). Como parâmetro, os autores sugerem que o valor de 0,36 é adequado para as áreas de ciências sociais e do comportamento. Assim, obteve-se um índice de 0,417 , garantindo que o modelo tem ajuste geral adequado.

Por fim, foi necessário verificar se as relações do modelo estrutural são significativas $(p \leq 0,05)$, calculando os testes $t$ de Student, conforme os dados da Tabela 2.

Tabela 2

Teste $t$ de Student

\begin{tabular}{|c|c|c|c|}
\hline Relação & Estatística de $t$ & Valores de $P$ & Conclusão \\
\hline Autonomia-> Comprometimento & 3,056 & 0,002 & Aceitar \\
\hline Autonomia-> Consentimento & 0,708 & 0,480 & Rejeitar \\
\hline Autonomia-> Entrincheiramento & 1,114 & 0,266 & Rejeitar \\
\hline Bem-Estar-> Comprometimento & 4,278 & 0,000 & Aceitar \\
\hline Bem-Estar-> Consentimento & 1,368 & 0,172 & Rejeitar \\
\hline Bem-Estar-> Entrincheiramento & 2,802 & 0,005 & Aceitar \\
\hline Conformidade-> Comprometimento & 0,927 & 0,354 & Rejeitar \\
\hline Conformidade-> Consentimento & 2,231 & 0,026 & Aceitar \\
\hline Conformidade-> Entrincheiramento & 0,440 & 0,660 & Rejeitar \\
\hline Domínio-> Comprometimento & 3,432 & 0,001 & Aceitar \\
\hline Domínio-> Consentimento & 0,705 & 0,481 & Rejeitar \\
\hline Domínio-> Entrincheiramento & 1,078 & 0,281 & Rejeitar \\
\hline Preocupação com a Coletividade-> Comprometimento & 3,625 & 0,000 & Aceitar \\
\hline Preocupação com a Coletividade-> Consentimento & 0,614 & 0,540 & Rejeitar \\
\hline Preocupação com a Coletividade-> Entrincheiramento & 1,091 & 0,276 & Rejeitar \\
\hline Prestigio-> Comprometimento & 1,281 & 0,201 & Rejeitar \\
\hline Prestigio-> Consentimento & 0,307 & 0,759 & Rejeitar \\
\hline Prestigio-> Entrincheiramento & 0,164 & 0,869 & Rejeitar \\
\hline Realização-> Comprometimento & 1,263 & 0,207 & Rejeitar \\
\hline Realização-> Consentimento & 2,643 & 0,008 & Aceitar \\
\hline Realização-> Entrincheiramento & 0,512 & 0,609 & Rejeitar \\
\hline Tradição-> Comprometimento & 1,086 & 0,278 & Rejeitar \\
\hline Tradição-> Consentimento & 0,875 & 0,382 & Rejeitar \\
\hline Tradição-> Entrincheiramento & 0,228 & 0,820 & Rejeitar \\
\hline Comprometimento-> Desempenho no Trabalho & 6,807 & 0,000 & Aceitar \\
\hline Consentimento-> Desempenho no Trabalho & 2,236 & 0,026 & Aceitar \\
\hline Entrincheiramento-> Desempenho no Trabalho & 1,202 & 0,230 & Rejeitar \\
\hline
\end{tabular}

Fonte: Elaborada pelos autores. 
Por meio da análise das relações significativas entre as variáveis (ver Tabela 2), na Figura 1, sistematizam-se os resultados encontrados, apresentando os coeficientes de caminho, que explicam o poder de influência de um construto sobre o outro e os coeficientes de determinação das relações do modelo (R2), que evidenciam o quanto um construto é explicado.

Figura 1

Modelo estrutural de teste de hipóteses

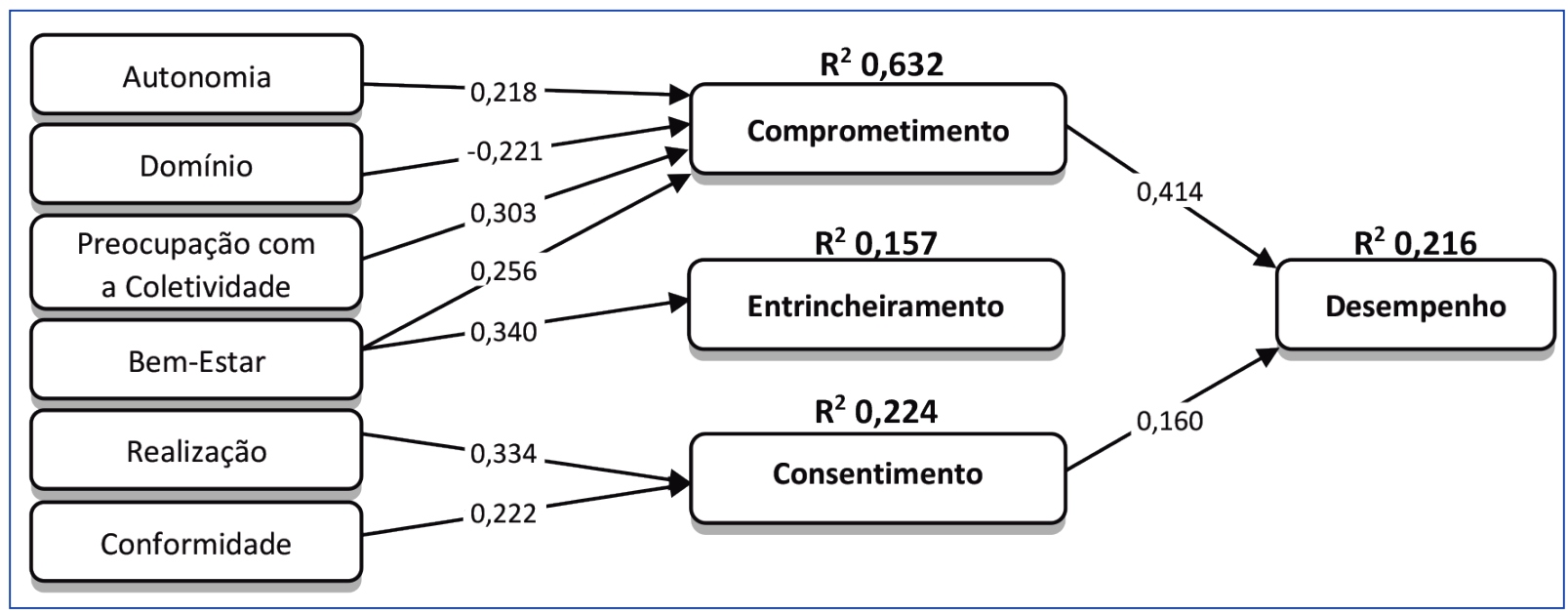

Fonte: Elaborada pelos autores.

A partir dos dados da Figura 1, visualiza-se que o coeficiente de determinação $\left(R^{2}\right)$, identificado para o comprometimento organizacional, indica que a variância do construto pode ser explicada em $63,2 \%$, tendo as dimensões de autonomia, domínio, preocupação com a coletividade e bem-estar como seus preditores.

Na dimensão preocupação com a coletividade $(\beta=0,303)$, evidencia-se a importância atribuída pela organização ao tratamento justo e igualitário nas relações com os seus colaboradores e com as demais partes próximas da comunidade (OLIVEIRA e TAMAYO, 2004). Parece correto afirmar que essa dimensão de valores organizacionais seja um preditor do comprometimento, uma vez que suas ações estão ligadas à promoção de um ambiente de trabalho que prioriza o bem-estar dos outros, necessário à vida em grupo e à relação da humanidade com os meios físico e social. Cabe destacar que essa dimensão apresentou o maior coeficiente de caminho, ou seja, configura-se como o maior determinante do vínculo afetivo.

A dimensão bem-estar no trabalho $(\beta=0,256)$, segundo Oliveira e Tamayo (2004), refere-se aos valores da organização que têm como meta promover a satisfação, o bem-estar e a qualidade de vida no trabalho, dirigidas a criar um ambiente de trabalho agradável e prazeroso. Em seu estudo, Tamayo (2005) buscou analisar os valores organizacionais que determinam o comprometimento afetivo, no qual também se observou que essa dimensão se configura como um preditor do comprometimento. Essas metas parecem compatíveis com o conceito de comprometimento organizacional, pois demostram a preocupação da organização com a felicidade de seus membros, por meio da promoção de ações diretamente ligadas a motivações, metas e aspirações do trabalhador, o que estimula o vínculo de comprometimento (TAMAYO, 2005).

A dimensão autonomia $(\beta=0,218)$ é caracterizada pelas metas organizacionais que priorizam o desafio e variedade no trabalho, a curiosidade, a criatividade e a inovação (OLIVEIRA e TAMAYO, 2004). Essa dimensão de valor organizacional também aparece no estudo de Tamayo (2005) como preditor do estabelecimento do vínculo de comprometimento afetivo. Para esse autor, o resultado é convergente com as perspectivas teóricas que explicam a dimensão autonomia, uma vez que seu conteúdo responde a necessidades, motivações e aspirações profundas do trabalhador e de qualquer ser humano.

A dimensão domínio $(\beta=-0,221)$ apresentou um $\beta$ negativo com o vínculo de comprometimento. Essa dimensão expressa as metas da organização que visam ao lucro, ser competitiva e dominar o mercado (OLIVEIRA e TAMAYO, 2004). Resultado semelhante foi identificado por Tamayo (2005), que também observou um $\beta$ negativo. Ao tentar explicar esse resultado, o autor destaca que essa dimensão inibe o comprometimento afetivo e a identificação com a organização, o que pode estar associado ao fato do trabalhador não se perceber como participante dos resultados obtidos pela organização. 
Esses resultados demostram que as metas axiológicas integradas às dimensões preocupação com a coletividade, bem-estar e autonomia favorecem esse vínculo, enquanto que a dimensão domínio, pelo contrário, o dificulta. Essa perspectiva é corroborada por estudo anterior (TAMAYO, 2005), no qual se observa que o comprometimento é antagonista com valores que colocam o foco na tradição e no domínio do mercado, enquanto que o prestígio da organização e de seus produtos/ serviços na sociedade e a importância dada à autonomia e ao bem-estar dos empregados constituem metas que favorecem o desenvolvimento do comprometimento.

Para o entrincheiramento, identificou-se que o valor bem-estar se configura como antecedente desse vínculo, demostrando poder explicativo de $15,7 \%$ da variância do construto. Ademais, o coeficiente de caminho revela que o valor bem-estar apresenta um grau de $34 \%(\beta=0,340)$ de influência sobre o vínculo de entrincheiramento do indivíduo com a organização. Nota-se que essa dimensão também apresentou influência sobre o comprometimento. Esse resultado, inicialmente, pode parecer pouco compreensível. Entretanto, o foco da dimensão bem-estar se encontra nas metas organizacionais dirigidas a desenvolver um ambiente de trabalho prazeroso, promovendo a satisfação e a qualidade de vida no trabalho (TAMAYO, 2005). Ao passo que essa dimensão se associa à ideia de felicidade do indivíduo por trabalhar na organização, ela aparece como um preditor do comprometimento. Por outro lado, a percepção do indivíduo de que a organização desenvolve programas de benefícios e qualidade de vida no trabalho, pode representar um fator importante para a sua decisão de permanecer, ligada à de perda desses benefícios associados à sua saída.

Analisando o consentimento organizacional, verifica-se que o modelo conseguiu explicar $22,4 \%$ da variância do construto, sendo que os coeficientes de caminho demostram que o consentimento é determinado em $33,4 \%(\beta=0,334)$ pelo valor realização e $22,2 \%(\beta=0,222)$ pelo valor conformidade.

O primeiro preditor, realização, caracteriza-se pela meta central focada no sucesso, alcançado por meio da competência da organização, que também reflete sobre os indivíduos que a compõem, seja em suas ações no ambiente de trabalho ou em atividades privadas (TAMAYO, 2005). O vínculo de consentimento carrega um forte apelo à obediência, representando um estado de dependência e subserviência, sendo o subordinado aquele que depende. No contexto organizacional, isso se reflete na rápida adesão às normas por parte do indivíduo que percebe a valorização da competência, pois ele acredita que esse é o seu papel para alcançar o sucesso da organização. É nessa relação de dependência, onde o trabalhador entende o sucesso individual acoplado ao sucesso da organização, que ele se torna mais disposto a consentir.

O segundo preditor do consentimento, a dimensão conformidade, prioriza aspectos como a cortesia e boas maneiras no trabalho e respeito às normas da organização, visando a controlar os comportamentos de seus empregados (OLIVEIRA e TAMAYO, 2004). Nota-se que a conformidade é um dos elementos fundamentais da estabilidade organizacional, englobando em suas metas o dispêndio de esforços da empresa para manter o cumprimento de ordens e regras. Além disso, a noção de conformidade limita a margem de ação do trabalhador, desqualificando, muitas vezes, o seu julgamento e habilidade de agir.

Como consequente do modelo, o desempenho no trabalho é predito pelo comprometimento e consentimento, onde a variância do construto pode ser explicada em $22,4 \%$ por esses dois vínculos organizacionais. Diante desses dados, constata-se que o comprometimento se caracteriza como o maior preditor do desempenho $(\beta=0,414)$. Isso significa dizer que o indivíduo com altos níveis de vinculação emocional, que se identifica com os valores organizacionais e se envolve com os papéis de trabalho, tende a desempenhar suas atividades laborais com maior sucesso. O que vai ao encontro do exposto por Mowday, Porter e Steers (1982) que explicam que o comprometimento definido como vínculo afetivo representa algo além da simples lealdade passiva a uma organização, envolvendo uma relação afetiva, na qual o trabalhador deseja dar algo de si para contribuir com a organização.

Observa-se, ainda, que o consentimento, apesar de em menor relevância do que o comprometimento, representou uma variável significativa no modelo para explicar o desempenho no trabalho $(\beta=0,160)$. Assim, a disposição do indivíduo para cumprir ordens, regras ou normas estabelecidas pela organização, devido à sua percepção de que a chefia sabe o que deve ser feito, influencia de maneira positiva o desempenho do indivíduo no trabalho. 0 entrincheiramento não apresentou relação significativa com o desempenho no trabalho.

Para sistematizar a discussão, o Quadro 2 apresenta a verificação das hipóteses da pesquisa. 


\section{Quadro 2 \\ Avaliação das hipóteses da pesquisa}

\begin{tabular}{|c|l|c|}
\hline \multicolumn{2}{|c|}{ Hipótese } & Conclusão \\
\hline H1 & $\begin{array}{l}\text { Trabalhadores que compartilham valores onde os tipos motivacionais dos polos autotranscedência } \\
\text { (preocupação com a coletividade) e abertura (autonomia e bem-estar) são mais fortes, estabelecem } \\
\text { predominantemente o vínculo de comprometimento organizacional. }\end{array}$ & Aceita-se \\
\hline H2 & $\begin{array}{l}\text { Trabalhadores que compartilham valores onde os tipos motivacionais dos polos autopromoção (bem- } \\
\text { estar, realização e domínio) e conservação (tradição e conformidade) são mais fortes, estabelecem } \\
\text { predominantemente o vínculo de entrincheiramento organizacional. }\end{array}$ & $\begin{array}{c}\text { Aceita-se } \\
\text { parcialmente }\end{array}$ \\
\hline H3 & $\begin{array}{l}\text { Trabalhadores que compartilham valores onde os tipos motivacionais do polo conservação (tradição } \\
\text { e conformidade) são mais fortes, estabelecem predominantemente o vínculo de consentimento } \\
\text { organizacional. }\end{array}$ & Aceita-se \\
\hline H4 & $\begin{array}{l}\text { Trabalhadores que estabelecem padrões de vínculos onde o comprometimento organizacional é } \\
\text { mais forte apresentam melhor desempenho no trabalho. }\end{array}$ & Aceita-se \\
\hline H5 & $\begin{array}{l}\text { Trabalhadores que estabelecem padrões de vínculos onde o entrincheiramento e consentimento } \\
\text { organizacionais são mais fortes apresentam menor desempenho no trabalho. }\end{array}$ & $\begin{array}{c}\text { Aceita-se } \\
\text { parcialmente }\end{array}$ \\
\hline
\end{tabular}

Fonte: Elaborado pelos autores.

\section{Fase II - Entrevistas com os gestores}

Acerca do perfil pessoal e ocupacional dos entrevistados, pode-se dizer que a faixa etária dos gestores entrevistados varia de 21 a 55 anos, sendo que 6 são do gênero feminino e 4 do gênero masculino. Quanto à escolaridade, verifica-se que 6 gestores possuem Ensino Superior completo, sendo a maioria na área de gestão. No que tange ao tempo de serviço na empresa, o tempo varia de 4 a 24 anos, já para o tempo no cargo de gerente varia entre 1 e 15 anos.

No intuito de explorar com maior profundidade a hierarquia de valores associada ao estabelecimento dos vínculos do indivíduo com a organização, os gestores receberam trinta fichas, organizadas em três perfis: comprometimento, entrincheiramento e consentimento. Após denominarem a partir das suas percepções cada um dos perfis, os gestores receberam outras oito fichas, referentes às dimensões de valores organizacionais, descritos de acordo com as conceituações de Oliveira e Tamayo (2004). Solicitou-se que o entrevistado determinasse com qual perfil de vínculo cada valor estava associado. As associações realizadas pelos gestores são sistematizadas na Tabela 3.

Tabela 3

Associações entre valores organizacionais e os vínculos organizacionais

\begin{tabular}{l|c|c|c}
\hline \multicolumn{1}{|c|}{ Valores } & Comprometimento & Entrincheiramento & Consentimento \\
\hline Autonomia & 10 & 0 & 0 \\
Bem-Estar & 7 & 3 & 0 \\
Conformidade & 3 & 3 & 4 \\
Domínio & 5 & 0 & 5 \\
Preocupação com a Coletividade & 8 & 2 & 0 \\
Prestígio & 8 & 2 & 0 \\
Realização & 10 & 0 & 0 \\
Tradição & 4 & 1 & 5 \\
\hline
\end{tabular}

Fonte: Elaborada pelos autores.

Como se visualiza na Tabela 3, os valores organizacionais obtiveram maior quantidade de associações com o vínculo de comprometimento. A fala dos gestores demonstra essa tendência: 
Eu vou colocar todos neste primeiro aqui [comprometimento] [...] acho que as pessoas inseguras $e$ passivas não têm muita identificação com os valores da organização. No geral, elas pensam somente nelas mesmas (ENTREVISTADO G5).

Porque eu acho que esses valores se encaixam perfeitamente nisso [comprometimento], o colaborador tem que ter a realização dele, tem que ter o bem-estar de trabalhar na empresa, a conformidade, 0 prestigio e a autonomia (ENTREVISTADO G7).

Ao analisar as falas, parece correto afirmar que o compartilhamento de valores organizacionais está diretamente associado aos padrões de vínculos organizacionais estabelecidos. Entretanto, os valores associados ao consentimento revelam que organizações compartilhando valores que priorizam aspectos como a competição e o domínio do mercado, respeito às normas e boas maneiras da organização e a manutenção das tradições e costumes, dimensões que compõem ou se aproximam do polo de conservação tendem a favorecer o vínculo de consentimento.

Ademais, as associações com o entrincheiramento permitem inferir que o desenvolvimento desse vínculo é favorecido por valores com uma orientação de adesão a convenções, a exemplo da obediência e formalidade. A percepção desses valores parece fomentar o vínculo instrumental e desvitalizar o vínculo afetivo, o que pode corroborar a associação do entrincheiramento com o valor conformidade.

O comprometimento assume uma configuração de prioridade de valores que se diferencia da hierarquia associada com as noções de estar entrincheirado ou consentido. Estar comprometido revela que o indivíduo se identifica com os valores compartilhados na organização. Essa identificação envolve a aceitação, tendo em vista a satisfação de um desejo de afiliação para com a organização, sendo que as pessoas adotam atitudes e comportamentos devido ao ajustamento entre as suas hierarquias de valores pessoais com os valores organizacionais (MOWDAY, PORTER e STEERS, 1982).

No segundo momento, questionou-se o gestor acerca de que tipo de desempenho era produzido por indivíduos de cada um dos três perfis, usando as próprias denominações do entrevistado. Os achados das percepções dos gestores são apresentados na Figura 2.

Figura 2

Associações entre os vínculos organizacionais e o desempenho no trabalho

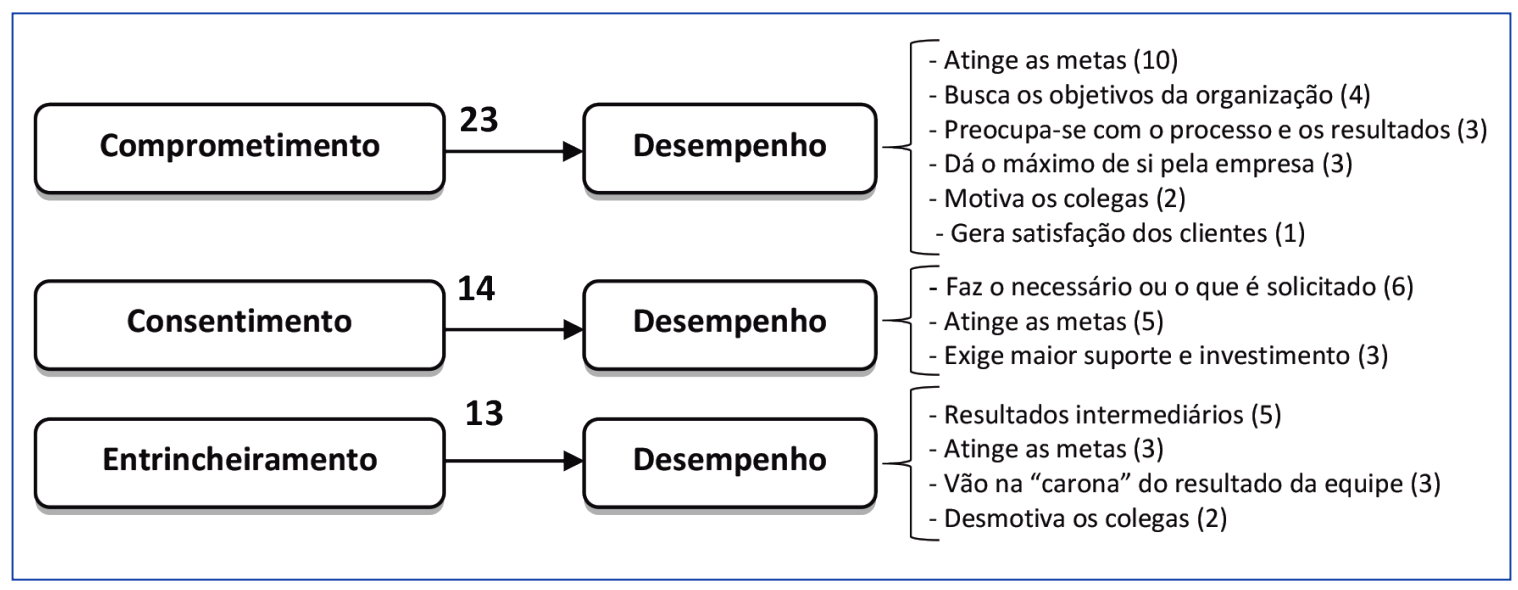

Fonte: Elaborada pelos autores.

Observa-se que o desempenho alcançado pelas noções de entrincheiramento e consentimento é voltado mais para informações com sentido negativo, enquanto que as relacionadas ao comprometimento apresentam sentido mais positivo. Resultado semelhante foi encontrado por Pinho, Bastos e Rowe (2015a), onde também predominaram noções para o entrincheiramento e consentimento que não favorecem ao crescimento nem dos indivíduos nem das organizações, dificultando o alcance dos objetivos de ambas as partes. 
As falas revelam esse sentido positivo atribuído ao comprometimento:

Se tem um funcionário que é comprometido com a empresa, ele te ajuda até na própria gestão, na parte de conversar com o cliente, ele atende melhor o cliente, ele preocupa-se com as metas de vendas, se não estávamos atingindo a meta ele vai e motiva os colegas, ele te ajuda em tudo (ENTREVISTADO G1).

É alguém que se importa com o papel que tá no chão, se é um papel reciclável para colocar fora ou se serve para alguma coisa. Esse é o sonho, não digo nem de gestor, mas de qualquer empresário (ENTREVISTADO G4).

Já o entrincheiramento e o consentimento foram vistos pelos gestores, de forma muito semelhante entre si, como tipos de vínculos que geram pouca contribuição para a organização:

Porque a pessoa que está mais acomodada, essa pessoa tu vai chegar e ela vai estar sentada em um canto, ela não vai estar disposta a te ajudar, é que nem tu colocar um jogador lesionado para jogar bola, ele não vai ter a mesma função [...] se tu tens laranjas podres na tua equipe, tudo tá ruim e que acabam dificultando um trabalho, às vezes não fazem e acabam contaminando os demais (ENTREVISTADO G1).

É, o resultado é fatal para a empresa, né, aqui nestes dois [entrincheiramento e consentimento]. No momento que um se acomodar, a usar o tanto faz e o tanto fez, isso gera sérios problemas (ENTREVISTADO G2).

Esses aqui [entrincheiramento e consentimento] eles acabam atingindo a metas de venda, até porque se não atingir ele tá fora, mas é aquela pessoa que eu preciso estar motivando o tempo inteiro, chamando para o trabalho, lembrando do que tem que fazer. Ele exige muito mais de mim do que essa daqui [comprometido] (ENTREVISTADO G7).

Verifica-se que ambos os vínculos, entrincheiramento e consentimento, podem estar associados ao atingimento das metas, entretanto, para isso, a organização precisa despender um suporte maior. Assim, parece correto afirmar que o trabalhador entrincheirado ou consentido, ao atingir as metas de produtividade, está contemplando a noção de desempenho voltado para a tarefa, ao se voltar para resultados mais localizados e específicos de suas atividades laborais. Esse resultado sustenta que trabalhadores entrincheirados e/ou consentidos também são produtivos, ao considerar como meta o desempenho específico e técnico das atividades laborais do trabalhador. Esse resultado reforça a análise de Klein, Molloy e Brinsfield (2012), que defendem que, para além do comprometimento, outros tipos de vínculos podem ser considerados apropriados, considerando o contexto e os objetivos da organização.

O indivíduo comprometido vai além das questões técnicas, como destacam os gestores, eles despendem esforços para questões mais estratégicas, preocupando-se com detalhes e fatores que contribuem para o alcance de objetivos e metas globais da organização, noções do desempenho voltado para o contexto. O que corrobora Maciel e Camargo (2016), ao explicarem que a ligação psicológica é importante para que os indivíduos reflitam sobre as ações de seus vínculos e que o resultado dessa reflexão influencia seu desempenho.

\section{CONSIDERAÇÕES FINAIS}

Acredita-se que foram identificadas importantes contribuições para o meio científico da área de administração, especialmente no que tange às temáticas do campo do comportamento organizacional, ao desenvolver um modelo que melhor explica como diferentes vínculos do indivíduo com a organização se assemelham e se diferenciam entre seus antecedentes e consequentes. A inclusão dos valores organizacionais e o desempenho no trabalho como variáveis antecedentes e consequentes dos vínculos organizacionais permitirá que futuras intervenções organizacionais, ao empregarem este modelo analítico, possam diagnosticar com maior precisão os tipos e as combinações de vinculações desenvolvidas por seus trabalhadores.

Esta pesquisa desenvolve uma importante contribuição ao identificar que determinados valores compartilhados pela organização são determinantes do tipo de vínculos que o indivíduo desenvolve com a organização, sendo que valores distintos influenciam vínculos distintos. Além disso, como consequente, infere-se que o tipo de vínculo organizacional estabelecido influencia o 
desempenho do indivíduo no trabalho. Os resultados da pesquisa constataram que o comprometimento é o vínculo com maior poder de explicação do construto do desempenho no trabalho. Os discursos dos gestores reforçam esse achado, associando o comprometimento a maiores índices de produtividade, motivação e empenho no trabalho. O consentimento apresentou uma relação significativa, porém, com coeficiente de caminho menor do que o comprometimento, com influência positiva sobre o desempenho no trabalho. $O$ entrincheiramento não apresentou relação significativa. Outros estudos poderão tentar repetir esse modelo para verificar sua consistência, inclusive o testando em diferentes contextos.

Outra contribuição importante desta pesquisa evidencia que trabalhadores entrincheirados e consentidos não são trabalhadores improdutivos, entretanto, a natureza desses vínculos exige um suporte maior da organização e dos gestores para que eles consigam desempenhar suas atividades com êxito. Sendo que, no geral, os esforços desses indivíduos se concentram no atingimento de metas individuais e de pouca contribuição para objetivos mais globais de desempenho da organização. Esse resultado sustenta um novo olhar da literatura sobre os consequentes dos vínculos de entrincheiramento e consentimento, que embora não estejam associados a níveis mais elevados de desempenho, podem ser considerados vínculos necessários e desejáveis em determinados contextos organizacionais. Isso é ainda mais interessante ao sustentar que níveis desses dois vínculos podem ser combinados com níveis de comprometimento, ao entender que os vínculos coexistem e não são excludentes entre si.

Para finalizar, este estudo não pode deixar de apontar seus limites. Em primeiro lugar, por se tratar de uma pesquisa restrita a determinado contexto específico. Destaca-se o fato do estudo abordar aspectos comportamentais, os quais possuem caráter subjetivo e complexo, sendo que foram utilizadas escalas atitudinais para a sua verificação. Ainda, observa-se que dados transversais foram utilizados neste estudo.

Portanto, para pesquisas futuras, sugere-se a realização de estudos longitudinais que permitam acompanhar tanto o estabelecimento quanto a manutenção do vínculo do indivíduo com a organização, explorando como os valores organizacionais exercem influência em ambos os fenômenos. Além disso, outros indicadores podem ser incluídos no modelo para enriquecer a compreensão do desempenho no trabalho. 


\section{REFERÊNCIAS}

BALSAN, L. A. G. et al. A influência do comprometimento, do entrincheiramento e do suporte à transferência de treinamento sobre o impacto do treinamento no trabalho. Revista de Administração da UFSM, v. 10, n. 6, p. 976-989, 2017.

BARDIN, L. Análise de conteúdo. Lisboa: Ed. 70, 2011.

BASTOS, A. V. B.; AGUIAR, C. V. N. Comprometimento organizacional. In: PUENTE-PALACIOS, K.; PEIXOTO, A. L. A. (Org.). Ferramentas de diagnóstico para organizações e trabalho: um olhar a partir da psicologia. Porto Alegre: Artmed, 2015. p. 78-91.

BECKER, H. S. Notes on the concept of commitment. American Journal of Sociology, v. 66, n. 1, p. 32-40, 1960.

CAMERON, K. S.; BRIGHT, D.; CAZA, A. Exploring the relationships between organizational virtuousness and performance. American Behavioral Scientist, v. 47, n. 6, p. 766-790, 2004.

CAMPBELL, J. P. Modeling the performance prediction problem in industrial and organizational psychology. In: DUNNETTE, M. D.; HOUGH, L. M. (Ed.). Handbook of industrial and organizational psychology. Palo Alto: Consulting Psychology Press, 1990. p. 687-732.

CARSON, K. D.; BEDEIAN, A. G. Career commitment: construction of a measure and examination of its psychometric properties. Journal of Vocational Behavior, v. 44, n. 3, p. 237-262, 1994.

CHIN, W. W. The partial least squares approach for structural equation modeling. In: MARCOULIDES, G. A. (Ed.). Modern methods for business research. London: Lawrence Erlbaum Associates, 1998. p. 295-336.

COHEN, J. Statistical power analysis for the behavioral sciences. New York: Psychology Press, 1998.

FOGAÇA, N. et al. Job performance analysis: scientific studies in the main journals of management and psychology from 2006 to 2015. Performance Improvement Quarterly, v. 30, n. 4, p. 231-247, 2018.

FORNELL, C.; LARCKER, D. F. Evaluating structural equation models with unobservable variables and measurement error. Journal of Marketing Research, v. 18, n. 1, p. 39-50, 1981.

GAO-URHAHN, X.; BIEMANN, T.; JAROS, S. J. How affective commitment to the organization changes over time: a longitudinal analysis of the reciprocal relationships between affective organizational commitment and income. Journal of Organizational Behavior, v. 37, p. 515-536, 2016.

HAIR JUNIOR, J. F. et al. A primer on partial least squares structural equation modeling (PLS-SEM). Los Angeles: Sage, 2013.

HARTER, J. K. et al. Causal impact of employee work perceptions on the bottom line of organizations. Perspectives on Psychological Science, v. 5, n. 4, p. 378-389, 2010.

HEAVEY, A. L.; HOLWERDA, J. A.; HAUSKNECHT, J. P. Causes and consequences of collective turnover: a meta-analytic review. Journal of Applied Psychology, v. 98, n. 3, 412-453, 2010.

KLEIN, H. J. Commitment in organizational contexts: introduction to the special issue. Journal of Organizational Behavior, v. 37, p. 489-493, 2016.

KLEIN, H. J.; MOLLOY, J. C.; BRINSFIELD, C. T. Recconceptualizing workplace commitment to redress a stretched construct: revisiting assumptions and removing confounds. Academy of Management Review, v. 37, p. 130-151, 2012.

MACIEL, C. O.; CAMARGO, C. Social connection in organizations: the effects of local ties on job engagement and performance. Revista de Administração, v. 51, p. 377-385, 2016.

MAIA, L. G.; BASTOS, A. V. B.; SOLINGER, O. N. Which factors make the difference for explaining growth in newcomer organizational commitment? A latent growth modeling approach. Journal of Organizational Behavior, v. 37, n. 4, p. 537-357, 2016.

MEdeIROS, C. A. F.; AlBUQUeRQUE, L. G. Comprometimento organizacional: um estudo de suas relações com características organizacionais e desempenho nas empresas hoteleiras. Revista Psicologia: Organizações e Trabalho, v. 5, n. 1, p. 35-64, 2005.

MEYER, J. P.; ALLEN, N. J. A three-component conceptualization of organizational commitment. Human Resource Management Review, v. 1, n. 1, p. 61-89, 1991.

MOWDAY, R. T.; PORTER, L. W.; STEERS, R. M. Employee-organization linkages: the psychology of commitment, absenteism and turnover. New York: Academic Press, 1982.

NASCIMENTO, T. G. et al. Valores organizacionais: uma análise bibliométrica da produção nacional do período de 2000 a 2013 na área de administração. Organizações em Contexto, v. 12, n. 24, p. 37-64, 2016.

OLIVEIRA, A. F.; TAMAYO, A. Inventário de perfis de valores organizacionais. Revista de Administração, v. 39, n. 2, p. 129-140, 2004.

PAIVA, K. C. M.; DUTRA, M. R. S. Valores organizacionais e valores do trabalho: um estudo com operadores de call center. Cadernos EBAPE.BR, Rio de Janeiro, v. 15, n. 1, p. 40-62, 2017.

PINHO, A. P. M. Comprometimento, entrincheiramento e consentimento organizacionais: uma análise destes vínculos, entre gestores e trabalhadores, de diferentes organizações. $256 \mathrm{f}$. Tese (Doutorado em Administração) - Universidade Federal da Bahia, Salvador, 2009.

PINHO, A. P. M.; BASTOS, A. V. B.; ROWE, D. E. O. Diferentes vínculos indivíduo-organização: explorando seus significados entre gestores. Revista de Administração Contemporânea, v. 19, n. 3, p. 288-304, 2015 a.

PINHO, A. P. M.; BASTOS, A. V. B.; ROWE, D. E. O. Diferentes vínculos organizacionais: explorando concepções, fatores organizacionais antecedentes e práticas de gestão. Organizações \& Sociedade, v. 22, n. 75, p. 659-680, 2015b.

QUEIROGA, F.; BORGES-ANDRADE, J. E.; COELHO JUNIOR, F. A. Desempenho no trabalho: escala de avaliação geral por meio de autopercepções. In: PUENTE-PALACIOS, K.; PEIXOTO, A. L. A. (Org.). Ferramentas de diagnóstico para organizações e trabalho: um olhar a partir da psicologia. Porto Alegre: Artmed, 2015. p. 36-45.

RINGLE, C. M.; SILVA, D.; BIDO, D. Modelagem de equações estruturais com utilização do SmartPLS. Revista Brasileira de Marketing, v. 3, n. 2, p. 54-71, 2014.

RODRIGUES, A. C. A.; BASTOS, A. V. B. Entrincheiramento organizacional: construção e validação da escala. Psicologia: Reflexão e Crítica, v. 25, n. 4 , p. 688-700, 2012. 
RODRIGUES, A. C. A.; BASTOS, A. V. B. Entrincheiramento organizacional. In: PUENTE-PALACIOS, K.; PEIXOTO, A. L. A. (Org.). Ferramentas de diagnóstico para organizações e trabalho: um olhar a partir da psicologia. Porto Alegre: Artmed, 2015. p. 107-120.

SCHEIBLE, A. C. F.; BASTOS, A. V. B. An examination of human resource management practices influence on organizational commitment and entrenchment. Brazilian Administration Review, v. 10, n. 1, p. 57-76, 2013.

SCHWARTZ, S. H. Universals in the content and structure of values: theoretical advances and empirical tests in 20 countries. In: ZANNA, M. (Org.). Advances in experimental social psychology. San Diego: Academic Press, 1992. p. 1-65.

SILVA, E. E. C.; BASTOS, A. V. B. Consentimento organizacional. In PUENTE-PALACIOS, K.; PEIXOTO, A. L. A. (Org.). Ferramentas de diagnóstico para organizações e trabalho: um olhar a partir da psicologia. Porto Alegre: Artmed, 2015. p. 92-106.

SONNENTAG, S.; FRESE, M. Performance concepts and performance theory. In: SONNENTAG, S. (Ed.). Psychology management of individual performance. Oxford: John Wiley \& Sons, 2002. p. 3-27.

TAMAYO, A. Valores organizacionais e comprometimento afetivo. Revista de Administração Mackenzie, v. 6, n. 3, p. 192213, 2005.

TAMAYO, A.; GONDIM, M. G. C. Escala de valores organizacionais. Revista de Administração, v. 31, n. 2, p. 62-72, 1996.

TENENHAUS, M. et al. PLS path modeling. Computational Statistics \& Data Analysis, v. 48, n. 1, p. 159-205, 2005. 